\title{
Narcissus -- The Evolution of Self-portraits in Image Times
}

\author{
Zhisheng Yan $^{1, a}$ \\ ${ }^{1}$ The College of Posts and Telecommunication, Wuhan Institute Of Technology, Wuhan, Hubei \\ Province, China \\ ayanzs2046@sina.com
}

Keywords: Image Times, self-consciousness, self-portraits, evolution.

\begin{abstract}
Self-portraits derive from portraiture. Initially, artists painted self-portraits to prove their identities; then, they used these paintings to show their unique personalities and life experiences. The psychological foundations of self-portraits are human's self-consciousness and their eternal pursuit of self-actualization. In Image Times, the popular and convenient image technology changes people's viewing patterns and the expressive forms of self-portraits. In Image Times, artists choose different ways to create self-portraits. Some artists, like Lucian Freud, still use mirrors to draw self-portraits; some artists such as Xiao-dong Liu use photos instead of mirrors; painters include Li-jun Fang and Min-jun Yue create hidden self-portraits; artists like Cindy Sherman and Nan Goldin directly use photography techniques; meanwhile, as the new form of self-portrait, selfies in social networks become popular carnival.
\end{abstract}

\section{Introduction}

Self-portrait is a kind of painting language, and it is originated from portraiture. In earlier times, artists' social status was relatively low. They belonged to painters, or artisans, and they did not have the rights to serve as the subjects of portraits. At the beginning of Renaissance, Giotto drew his image and name consciously on his paintings. The image replaced artist's signature, like Chinese painters' seals in their completed works. Artists' personal consciousness was awakening. Later, due to the continuous efforts of Leonardo Da Vinci and others, the social status of artists rose. Since then, artists were respected like scientists and philosophers. Some citizens admired artists like they admiring Gods. Artists' social roles changed from craftsmen at the bottom of society to intellectuals. With the improvement of artists' social status and the start of their self-consciousness, modern self-portraits appeared.

\section{Self-portraits before Image Times}

Rembrandt left us a series of self-portraits. It can be said that these self-portraits are records of his wonderful life. He was a successful and fashionable painter in the period of youth; while in his old days, Rembrandt was lonely and bankrupt. The tragedy of bankruptcy and the unyielding will of a truly great man reflected in his appearance. These self-portraits formed a unique autobiography. Rembrandt's self-portraits were absolutely faithful. He observed himself in the mirror. Without deliberate gestures, the painter observed his face carefully. He was always ready to penetrate humans' faces and find their inner secrets. Then, he interpreted these information in his paintings. "We are quite familiar with Rembrandt's keen and determined eyes in his self-portraits. His eyes are able to discern peoples' inner life." [1]

In Edvard Munch's Self-Portrait with Brushes drawn in 1904, the painter held a brush in his right hand. He was confident and full of vigor, [4] but nervous atmosphere can also be found in the picture. Although Munch lived to eighty years old, illness and death haunted him for most of his lifetime. In his youth, his mother and sister died of lung disease. He was also infected with a variety of diseases, so the theme of disease and death repeatedly appeared in his works. In this self-portrait, the artist used abstract colors and bold lines like fauves, which illustrated the artist's talent. His appearance was natural and distinctive, confident and nervous. Meanwhile, he "still looks healthy, powerful and optimistic". [2] 
The historical evolution of Western self-portraits started from artists' purposes to prove their identities. Then they wanted to show their unique and imperfect bodies through these paintings. At last, artists used these self-portraits to show their unique personalities and tell their life stories.

\section{Image Times}

Before Image Times, people used words and pictures to record, express and spread information. At that time, images were reflection of reality, because they came from reality. In Ban-qiao Zheng's theory of "bamboo in the eyes, bamboo in the mind, and bamboo in the picture", the final image came from "bamboo in the eyes", namely the bamboo is reality. The invention of cameras led the world into Image Times, realistic and detailed photos make people notice information which they could not see before. Photos can provide information, that's the value of photos. Photos with high resolution can reveal more details than human eyes.

Meanwhile, photos can be regarded as "proofs" [3] of reality. They are definitely faithful to the facts. Thus, photos can be separated with the subject. "Images in the photos can be separated from the context, and represent themselves in different ways". [4] Moreover, the special relationship between photographs and reality makes people believe that when they looking at a picture, they can see the reality. People will say "they are my parents" when they looking pictures, but what they really see is photos, not human beings. Since then, camera lenses replace human eyes, looking at photos becomes looking at the reality. Photos replace the reality. At the same time, people's watching consciousness is also replaced. Instead of looking at reality, now we only look at photos, and we even try to understand the world in this way. Photos become the reality, or the world itself.

With the development of computer technology, now we can modify photos easily through digital techniques. It is much more convenient than the previous way of modifying photos in darkrooms. But these techniques destroy the foundation of photos. In the past, there must be something in reality in front of the camera when we taking pictures. But now it is easy to "fake" pictures; images in these pictures may do not exist at all. "It also creates the facts", [5] and people cannot tell these false information easily. Hence, photos separate themselves away from the reality, and form a surreal image world. "It is social and time distances imposed and connected by photographs that are surreal." [6] These distances also separate us from reality. We live in the world of images, which is a surreal one. These images are more virtual than realistic, and they changes the concept of reality. Modern media boosts the development of image world. Some people even propose that, these things cannot be found on Google do not exist in reality. In Image Times, images are not reflection of reality or society. On the contrary, the reality and society are reflection of image. For instance, the world popular Cosplay activities are reflection and simulation of image world. Under that situation, "the false reality is planned, fabricated and composited by media; it supplants the real experience of daily life, and hinders people's understanding of the truth". [7]

\section{Evolution of Self-portrait in Image Times}

Before Image Times, artists observed their bodies through the mirror, and then painted self-portraits, "If there is no mirror, there will be no real self-portraits. So historians should pay attention to the history of mirror making technique." [8] But in the Image Times, great changes take place. Artists can continue to use mirrors, or adopt new approaches like using photos, creating hidden portraits or shooting photos directly. Even civilians began to post selfies on the Internet and share them with the others.

Using mirrors. It is a traditional way to draw self-portraits by using mirrors. When Albrecht Dürer was 13 years old, he drew a self-portrait and wrote down a few lines, "I looked the mirror and painted the picture. This is a self-portrait." In 1552, Sofonisba Anguissola drew a self-portrait and inscribed, "in Cremona, Sofonisba Anguissola looked at the mirror, and painted this works by her hands". These are specific documentary evidence of creating self-portraits with the help of mirrors.

Lucian Freud was an artist who insists on sketching direct from nature. His spirit of "sketching is the creation" [9] reflected in his works. In his late years, he created a series of self-portraits. In the 
work of Self-portrait, Lucian Freud stood in his studio, naked, with brush and palette in his hands. The scene shows his professional dignity. He repeated laid the pigment, and use thick lines to show the spirit of loneliness, nervousness and anxiety of contemporary people. Freud was an intensely private and guarded man, and he intended to explore the deep inner world of people through those lonely individuals. His self-portraits, like his previous works, are works with spiritual connotation.

Using photos. In Image Times, photos are easy to access. So some artists choose photos with their own images to create self-portraits.

Xiao-dong Liu is an artist who likes to use photos. Most of his works are drawn on the basis of photos. With the use of sketching language, his works maintain a strong sense of the scene feeling. In 1989, he drew the painting of Pastorale based on a photo taken in his hometown, which located in the northeast of China. In this picture, the sunshine was bright; the painter and his wife, Hong $\mathrm{Yu}$, is standing in front of the red brick house of a small train station. Trees and fields can be found in distance. These photo based works are visual fragments, which show accidental, broken and encounter scenes. Unlike realism painters who mechanical draw pictures according to photos, Xiao-dong Liu takes photos as reference and development sources. He can utilize the information resources in these photos. For him, photos are methods to access information, rather than the reality itself.

Hidden self-portraits. Self-portrait is an important category of Chinese contemporary art, reflecting artists' strong desire to recreate themselves through visual images. Some artists do not directly express or depict their own images or mental states. They use a vague way to draw their self-images on the screen. These images are both visible and invisible; they do exist and do not exist at the same time. Like the yawning young man with bare head in is Li-jun Fang's works. In these works, the self-images are means, not ends; "egos" are represented with the help of "images".

The subjects of the hidden self-portraits are no longer real human beings, but a freedom illusion. In a sense, the distorted faces in these works can be regarded as masks; people use them to act and disguise themselves. These masks blur the boundary of portraits and self-portraits. These artists choose to hide the similarities and distinctions of people, rather than highlight them. Of course, these ambiguous images associate with our self-authenticity. Although they distort our images in reality, "distortion is the reality itself". [10] These images are created for self-expression. Through this unique strategy, artists can build their contemporary images.

Direct photography. Camera helps people to take pictures about themselves directly. Then, selfies are created. Selfies are a kind of artistic expression which originated from artists' self-portraits. Increasing artists began to use camera, and selfie has become a relatively mature artistic form. Like self-portrait, selfies are expression and description of our images. With the developed technology in Image Times, cameras replace painting materials; people now can easily access to their images.

Cindy Sherman creates her works through taking selfies. She dresses as different characters, like a passenger on the bus or a little girl, and then takes selfies. These pictures look like movie screenshot. She said, "I divide myself into many different parts. The girl in the countryside is one part...... the career woman is one part, while the artist in camera studio is another part." [11] Cindy Sherman's selfies have social significance as well as personal meanings. They reflect the features of consumer society. A variety of roles directly point to the many cultural, social and personal factors, and express personal opinions as well as social attitudes.

Network selfie. Technological progress and revolution bring changes in cultural forms, as well as communication methods and contents. With the development of digital technology, especially the rapid development of Internet technology, network society comes into being quickly. Under that situation, selfies transform from a serious art form into popular carnival. Everyone can involve in this carnival. Based on social network platforms, people take selfies, and then modify these pictures through Photoshop software to beautify their images. These behaviors affect the reliability of pictures; photos become tools to "cheat the others" [12]. The starting point and purpose of network selfies are entertainment and sharing; these photos are taken, spread and appreciated on the network, and has form the "virtual reality" which is completely different from the past. These photos definitely reflect narcissistic complex. 
Selfies become popular carnival, and everyone can involve in it; self-portraits and photography changes from professional and elite activities into democratic behaviors. The purposes and contents of photograph also change. All the mainstream, authoritative, classic and traditional works, words and expressions can be deconstructed at any time. "They do not directly resist or oppose the authority; they use methods like collage, parody, irony and metaphor to ridicule the authority, and gain their pleasures."[13] These selfies show attitudes of involvement, expression, interaction and sharing. Their personal attitudes, thoughts and feelings are embodied in these pictures, together with the intervention and expression of reality. Rene Descartes said, "I think, therefore I am"; these people say, "I shoot, therefore I am".

\section{Conclusions}

The question of ego is a part of essence problem of human being. [14] Artists use self-portraits to check, understand, express and interpret their own states; these pictures reflect their self-awareness and their eternal pursuit of self-values. The tasks of portraiture are depicting the spirit of living men and their innermost feelings. In self-portraits, artists depict their own images; and at the same time, they express their soul and spirit, as well as the thoughts and questions of human being.

In Greek mythology, Narcissus was a handsome young man. He accidentally noticed his reflection in the water, and was obsessed by his beauty. The obsession resulted in depression. His behavior can be regarded as taking selfies by the water. In Image Times, self-portraits changes with people's viewing patterns. These changes have different dimensions, including technical perspective like using photos and shooting photos directly, and formal perspective like creating hidden self-portraits. Some artists stick to the traditional way of using mirrors, while some others definitely reform the tradition by taking network selfies. These are presentation and expression of humans' self-consciousness, and show people's eternal consciousness of knowing themselves.

\section{References}

[1] E.H. Gombrich, The Story of Art. J.Z. Fan (Trs.), X. Lin (Eds.), SDX Joint Publishing Company, Beijing, 1999, p423.

[2] H.H. Arnason, The Western Modern Art History, D.N. Zou, Z.S. Ba and T. Liu (Trs.), Y.L. Shen (Eds.), Tianjin People's Fine Arts Publishing House, Tianjin, 1994, p157.

[3] R. Barthes, Camera Lucida: Reflections on Photography, K.F. Zhao (Trs.), Culture and Art Publishing House, Beijing, 2003, p140.

[4] N. Postman, Amusing Ourselves to Death; The Disappearance of Childhood, Y. Zhang, Y.T. Wu (Trs.), Guangxi Normal University Press, Guilin, 2009, p67.

[5] L. Wells, Photography: A Critical Introduction, K. Fu and J. Zuo (Trs.), Posts and Telecommunications Press, Beijing, 2012, p30.

[6] S. Sontag, On Photography, H.H. Ai, J.X. Mao (Trs.), Hunan Fine Arts Publishing House, Changsha, 1999, p73.

[7] D. Kellner, Media Spectacle, A.B. Shi (Trs.), Tsinghua University press, Beijing, 2003, p18.

[8] D. Hockney, Secret Knowledge: Rediscovering the Lost Techniques of the Old Masters, M.C. Wan, J. Zhang and Y.L. Lan (Trs.), Zhejiang People's Fine Arts Publishing House, Hangzhou, 2014, p261.

[9] Z.S. Yan, Rethinking the significance of sketching in Image Times, J. Arts Criticism. 9 (2010) 40.

[10] M.L. Gao, Walls: History and boundary of Chinese Contemporary Arts, China Renmin University Press Beijing, 2006, p1. 
[11] G.B. Zhao, Cindy Sherman, L.H. Liu (Eds.), Jilin Fine Arts Publishing House, Changchun, 2010, p19.

[12] Modifying photos are nothing new. Techniques which can modify, distort and beautify photos were invented in the early development of photography. But these were not popular before Social Media Era.

[13] Y. Chen. Paike: Making Dazzling and Narcissism, Suzhou University Press, Suzhou, 2012, p11.

[14] И.С.Кон. Theory of Ego: Individuals and Self Consciousness, J.H. Tong, G.E. Fan and H.Z. Xu (Trs.) SDX Joint Publishing Company, Beijing, 1987, p21. 